\title{
Determination of Pavement Rehabilitation Activities through a Permutation Algorithm
}

\author{
Sangyum Lee, ${ }^{1}$ Sungho Mun, ${ }^{2}$ and Hyungchul Moon ${ }^{3}$ \\ ${ }^{1}$ Road Management Division, Seoul Metropolitan Government, Republic of Korea \\ ${ }^{2}$ Department of Civil Engineering, Seoul National University of Science \& Technology, Republic of Korea \\ ${ }^{3}$ ROADTECH Corporation, Ansan-si, Gyunggi-do, Republic of Korea
}

Correspondence should be addressed to Sungho Mun; smun@seoultech.ac.kr

Received 15 April 2013; Accepted 29 May 2013

Academic Editor: Zong Woo Geem

Copyright (C) 2013 Sangyum Lee et al. This is an open access article distributed under the Creative Commons Attribution License, which permits unrestricted use, distribution, and reproduction in any medium, provided the original work is properly cited.

\begin{abstract}
This paper presents a mathematical programming model for optimal pavement rehabilitation planning. The model maximized the rehabilitation area through a newly developed permutation algorithm, based on the procedures outlined in the harmony search (HS) algorithm. Additionally, the proposed algorithm was based on an optimal solution method for the problem of multilocation rehabilitation activities on pavement structure, using empirical deterioration and rehabilitation effectiveness models, according to a limited maintenance budget. Thus, nonlinear pavement performance and rehabilitation activity decision models were used to maximize the objective functions of the rehabilitation area within a limited budget, through the permutation algorithm. Our results showed that the heuristic permutation algorithm provided a good optimum in terms of maximizing the rehabilitation area, compared with a method of the worst-first maintenance currently used in Seoul.
\end{abstract}

\section{Introduction}

This study involves the objective function of the rehabilitation area to be maximized, using the evaluation model of pavement performance, which is the structural and functional behavior of a road section or length of pavement; furthermore, using budget limitations for pavement rehabilitation, the more deteriorated areas are fixed, based on solving a maximizing problem in this paper. Regression analysis was used to characterize the structural performance under rutting and fatigue deterioration conditions (Figure 1).

The functional behavior of the pavement is based on the passenger's perception of the level of service of the pavement and is related to the comfort quality (i.e., smoothness and safety) of the ride. Pavement riding quality was determined in terms of the international roughness index (IRI), as shown in Figure 2. The measurement of riding serviceability of the pavement used the quarter-car simulation model, which accounts for the sprung mass of the vehicle body, the suspension spring and damper constants, the unsprung mass of the suspension, tire, and wheel, and the spring constant of the tire [1]. For the calculation of IRI, the road profile was filtered using the quarter-car simulation, with specific parameter values that corresponded to a simulation speed of $80 \mathrm{~km} \mathrm{~h}^{-1}$ (Figure 2) [2].

In this study, we created an efficient optimization method, based on the heuristic permutation algorithm, to determine the optimum pavement rehabilitation area for a specified budget. The proposed algorithm, based on the harmony search algorithm [3-6], was developed from field measurement data obtained from a road survey vehicle and quartercar simulations. Section 2 presents a review of the relevant literature of structural and functional deterioration models. Section 3 describes the determination of the optimum rehabilitation area, using the permutation algorithm. Finally, Section 4 presents the application of a case study.

\section{Structural and Functional Deterioration Models}

Much attention has been paid to the deterioration model of pavement performance in terms of fatigue cracking and rut depth as permanent deformation [5]. In this approach, 


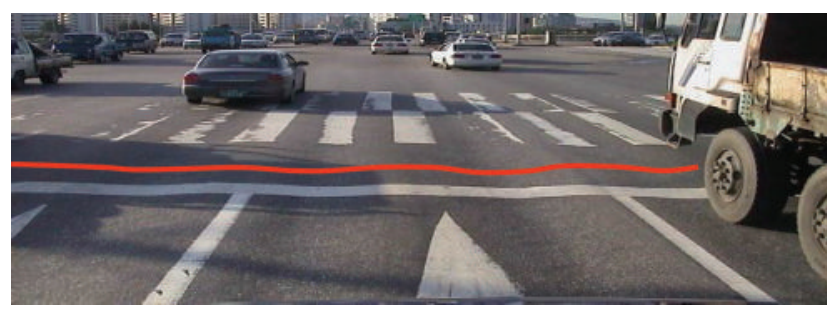

(a)

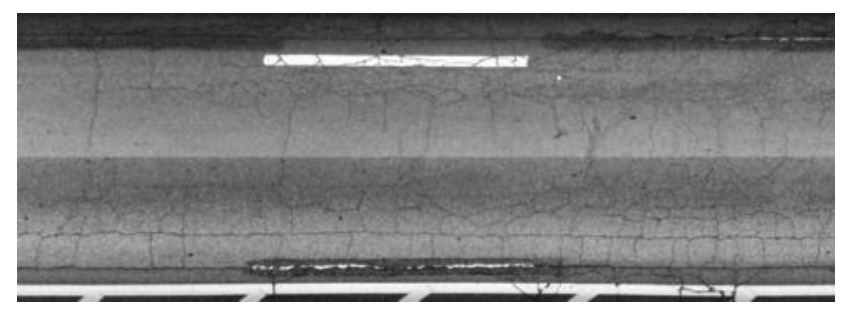

(b)

FIGURE 1: Pavement distress: (a) rutting and (b) fatigue cracking.

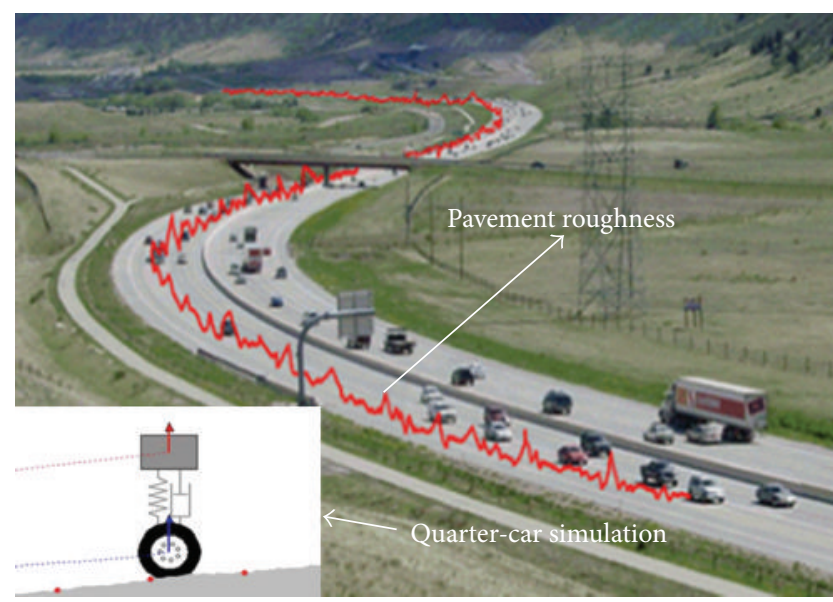

Figure 2: International roughness index (IRI) determination through measurement of pavement roughness and quarter-car simulation.

the initial value of fatigue cracking is assigned a value of 10 (i.e., undamaged status), which decreases as described in (1):

$$
\mathrm{SPI}_{\text {crack }}=10-1.667 \cdot \mathrm{Cr}^{0.38}
$$

where SPI ${ }_{\text {crack }}$ is the Seoul pavement index (SPI) of the crack deterioration model for Seoul city, and Cr is the percentage of crack area of the pavement surface. The SPI crack $_{\text {decreases }}$ as the crack area increases.

The deterioration model related to rut depth is based on the averaged measurement of permanent deformation in specific pavement sections and is given as

$$
\mathrm{SPI}_{\mathrm{RD}}=10-0.267 \cdot \mathrm{RD},
$$

where $\mathrm{SPI}_{\mathrm{RD}}$ is the SPI of the rutting deterioration model in Seoul city, and RD is the rut depth ( $\mathrm{mm})$. The intact status of 10 (the initial value) decreases as the rut depth increases.

The functional pavement condition of the IRI value has a similar form as the structural deterioration models specified in (1) and (2):

$$
\mathrm{SPI}_{\mathrm{IRI}}=10-0.727 \cdot \mathrm{IRI},
$$

where $\mathrm{SPI}_{\mathrm{IRI}}$ is the functional pavement deterioration index of the IRI $\left(\mathrm{m} \mathrm{km}^{-1}\right)$ value, related to ride quality, and IRI is the international roughness index. The unit for the IRI of meters per kilometer $\left(\mathrm{m} \mathrm{km}^{-1}\right)$ is based on the slope measurement of the pavement roughness.

Finally, the combination model for determining pavement integrity considers both structural and functional deterioration:

$$
\begin{gathered}
\mathrm{SPI}=10-\left[\left(10-\mathrm{SPI}_{\text {crack }}\right)^{5}+\left(10-\mathrm{SPI}_{\mathrm{RD}}\right)^{5}\right. \\
\left.+\left(10-\mathrm{SPI}_{\mathrm{IRI}}\right)^{5}\right]^{1 / 5},
\end{gathered}
$$

where SPI is the integral SPI consisting of a combination of the structural and functional SPIs, including fatigue cracking, rutting, and IRI conditions, for surface deterioration of the pavement in Seoul. The threshold SPI value for pavement rehabilitation is 5 .

Figure 3 shows three cases; each case is dependent on one of the indices, $\mathrm{SPI}_{\text {crack}}, \mathrm{SPI}_{\mathrm{RD}}$, or $\mathrm{SPI}_{\mathrm{IRI}}$, while the other two indices remain constant. For example, the distress curve of the integral SPI can be calculated for a fixed value of $3 \mathrm{~mm}$ for the rut depth and $2 \mathrm{~m} \mathrm{~km}^{-1}$ for the IRI value, as shown in Figure 3(a). The distress curves of the integral SPIs shown in Figures 3(b) and 3(c) are obtained from fixed values of 1\% fatigue cracking and $2 \mathrm{~m} \mathrm{~km}^{-1}$ IRI and $1 \%$ fatigue cracking and $3 \mathrm{~mm}$ rutting, respectively.

If the SPI integral is $<5$, then the rut depth, cracking area, and IRI are checked to determine the appropriate rehabilitation technique. The procedure is given as follows: (1) check whether the rut depth is $\geq 18 \mathrm{~mm}$; if so, a modified asphalt overlay of $15 \mathrm{~cm}$ thickness is applied; (2) check whether the crack area on the pavement surface is $\geq 30 \%$; if so, a modified asphalt overlay of $10 \mathrm{~cm}$ thickness is applied; if $17 \% \leq$ crack area $<30 \%$, then a modified asphalt overlay of $5-\mathrm{cm}$ thickness is applied; (3) check whether the IRI is $\geq 7.3 \mathrm{~m} \mathrm{~km}^{-1}$; if so, a modified asphalt overlay of $5 \mathrm{~cm}$ thickness is applied; (4) for all other cases, a traditional asphalt overlay of $5 \mathrm{~cm}$ thickness is applied. The costs of the above rehabilitation overlays are shown in Table 1.

\section{Permutation Algorithm}

The permutation algorithm conceptualizes a behavioral phenomenon of randomly generated permutations, in which a randomly selected permutation set continues to improve the optimization solution, similar to the search for a better state of harmony [6,7]. This section describes the proposed permutation algorithm, based on the heuristic algorithm, 


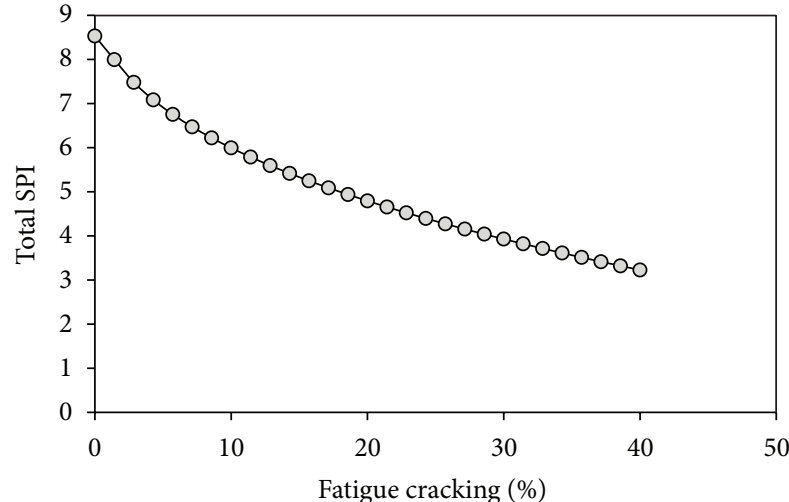

(a)

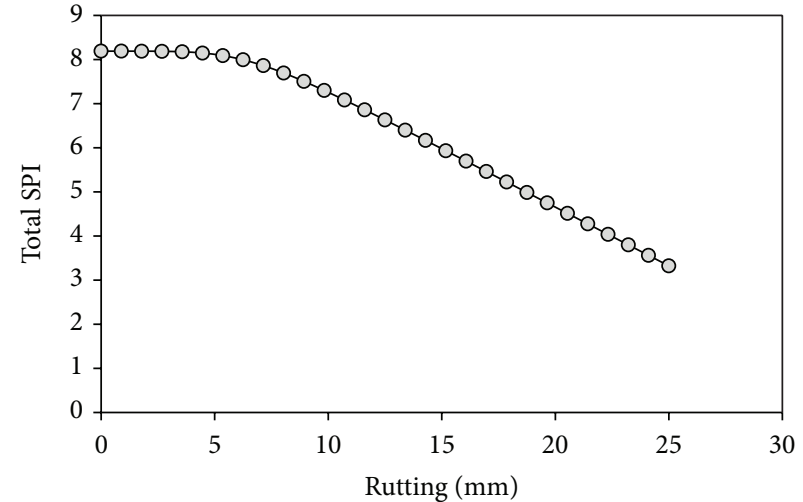

(b)

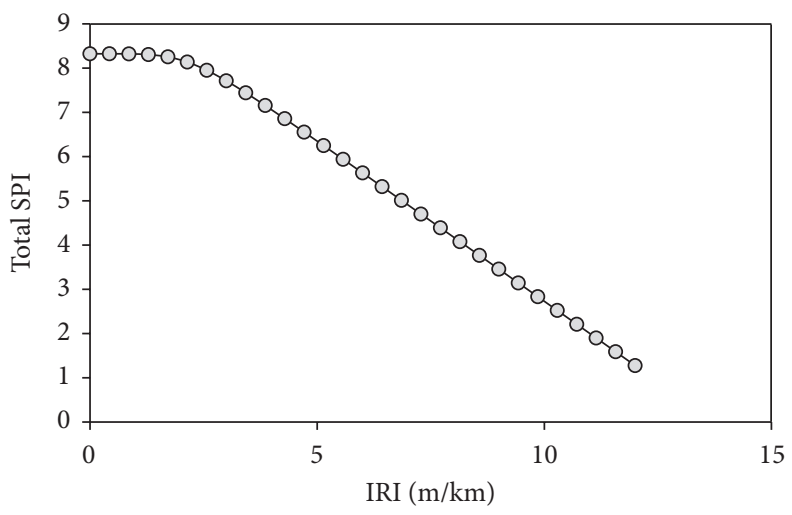

(c)

FIGURE 3: Distress models: (a) fatigue cracking, (b) rutting, and (c) IRI.

TABLE 1: Costs of the rehabilitation overlays.

\begin{tabular}{|c|c|c|c|c|}
\hline $\begin{array}{l}\text { Rehabilitation } \\
\text { method }\end{array}$ & $\begin{array}{l}\text { Modified asphalt overlay of } \\
15 \mathrm{~cm}\end{array}$ & $\begin{array}{l}\text { Modified asphalt overlay of } \\
10 \mathrm{~cm}\end{array}$ & $\begin{array}{l}\text { Modified asphalt overlay of } \\
5 \mathrm{~cm}\end{array}$ & $\begin{array}{c}\text { General asphalt overlay of } \\
5 \mathrm{~cm} \\
\end{array}$ \\
\hline $\begin{array}{l}\text { Cost } \\
\left.\text { (million won/are }{ }^{*}\right)\end{array}$ & 5.6 & 4.2 & 2.5 & 2.2 \\
\hline
\end{tabular}

${ }^{*}$ Are is $100 \mathrm{~m}^{2}$.

which searches for an optimized solution. First, we present an application overview of the permutation algorithm, used to formulate the solution vectors for optimization. The object function is then evaluated. Finally, the application setup of the permutation algorithm is explained in terms of pavement rehabilitation.

3.1. Algorithm Procedure. Budget limitations for pavement rehabilitation in Seoul city require that the worst deteriorated areas are fixed first (worst-first maintenance) with an asphalt overlay, followed by subsequent areas with slightly less wear. The worst-first maintenance is currently used in Seoul city. However, this rehabilitation procedure has not been evaluated to determine whether or not it provides an increase in the overall averaged SPI value, an indicator of the overall pavement surface condition for Seoul city. The more deteriorated pavement surface areas should be rehabilitated through the permutation algorithm to optimize resources within a limited budget, compared with the current rehabilitation method, such as worst-first maintenance.

The procedure for the permutation algorithm consists of Steps 1 through 4. Algorithm preparation is set up in Step 1, as follows: the sectional SPI values of (4) are calculated, regarding the number of deteriorated sections; these values are then checked to determine whether or not they are below the threshold value of 5 , to decide the appropriate rehabilitation method; the deteriorated sections below an SPI value of 5 are then grouped; the deteriorated sections are sorted in ascending order, in terms of their SPI values; and finally, the worst-first maintenance sequence is set up.

In Step 2, the optimization problem is specified as follows:

Maximize $\quad$ Area $_{T}=\sum_{i=1}^{N}$ DeArea $_{i}$

subject to $L_{\text {Budget}}$, 
TABLE 2: Setup of the measured field data used for the heuristic permutation algorithm.

\begin{tabular}{lccccc}
\hline Section number & Road width $(\mathrm{m})$ & Road length $(\mathrm{m})$ & IRI $(\mathrm{m} / \mathrm{km})$ & Rutting $(\mathrm{mm})$ & Fatigue cracking $(\%)$ \\
\hline 1 & 4 & 200 & 10.55 & 7.76 & 4.69 \\
2 & 23 & 380 & 10.02 & 13.27 & 8.02 \\
3 & 23 & 600 & 9.29 & 6.80 & 3.43 \\
$\vdots$ & $\vdots$ & $\vdots$ & $\vdots$ & $\vdots$ & $\vdots$ \\
150 & 18 & 320 & 5.92 & 4.33 & 5.64 \\
\hline
\end{tabular}

where DeArea ${ }_{i}$ is the $i$ th deteriorated area, which is computed by multiplying the length of the area by its width. For example, the worst deteriorated area, which shows the lowest value of SPI, can be found in $\operatorname{DeArea}_{1}\left(\right.$ e.g., $i=1$ ). $L_{\text {Budget }}$ is the specified budget limitation.

In Step 3, a sorted column vector of the worst-first sequence in Step 1 is filled in the first row of a permutation memory (PM) matrix. The second row of the PM matrix is filled with a randomly generated permutation vector, consisting of the columns of the rehabilitation sections covered by the limited budget, as well as the corresponding total area, Area $_{T}$, as shown in

$$
\mathrm{PM}=\left[\begin{array}{cccccc|c}
x_{1}^{1} & x_{2}^{1} & x_{3}^{1} & \cdots & \cdots & x_{N_{T}}^{1} & \operatorname{Area}_{T}^{1} \\
x_{11}^{2} & x_{N_{T}}^{2} & x_{3}^{2} & \cdots & x_{7}^{2} & \cdots & \operatorname{Area}_{T}^{2}
\end{array}\right],
$$

where the first row represents the sorted column vector of the worst-first maintenance (e.g., $x_{2}^{1}$ is the first row (superscript) and the second worst deterioration area (subscript)); the second row represents the randomly generated permutation vector; $N_{T}$ is the total number of deteriorated sections which show an SPI value $<5$, based on satisfying the limited city budget; and Area $_{T}$ is the total deteriorated area. Some of the deteriorated sections will not be rehabilitated due to budget constraints.

In Step 4, a comparison process is carried out between the first and second rows in (6). Firstly, the second row in the PM matrix is randomly permutated until $\mathrm{Area}_{T}^{2}$ is larger than $\operatorname{Area}_{T}^{1}$ in (6). Secondly, a new permutation vector is randomly generated until the new permutation set provides a larger rehabilitation area in comparison with the second row, as given in

$$
X^{\mathrm{New}}=\left(x_{32}^{\mathrm{New}}, x_{7}^{\mathrm{New}}, x_{19}^{\mathrm{New}}, \ldots, x_{8}^{\mathrm{New}}, \ldots\right) .
$$

If the new permutation set satisfies the above criterion of the larger rehabilitation area then, it can be added to the third row in the PM matrix, as shown in (7) and

$$
\mathrm{PM}=\left[\begin{array}{cccccc|c}
x_{1}^{1} & x_{2}^{1} & x_{3}^{1} & \cdots & \cdots & x_{N_{T}}^{1} & \mathrm{Area}_{T}^{1} \\
x_{11}^{2} & x_{N_{T}}^{2} & x_{3}^{2} & \cdots & x_{7}^{2} & \cdots & \operatorname{Area}_{T}^{2} \\
x_{32}^{3} & x_{7}^{3} & x_{19}^{3} & \cdots & x_{8}^{3} & \cdots & \operatorname{Area}_{T}^{3} \\
\cdot & \cdot & \cdot & \cdot & \cdot & \cdot & \cdot
\end{array}\right]
$$

Additionally, based on an evaluation of the objective function value of Area $_{T}$ in (5), another new permutation set is randomly searched to update the fourth row of the PM matrix, consisting of a larger rehabilitation area, compared with the third row. Finally, if the stopping criterion (i.e., the maximum number of iterations) is satisfied, the procedure of adding better permutation sets into the PM matrix is terminated. Otherwise, Step 4 is repeated.

\subsection{Application Setup for the Maximized Rehabilitation Area} of Deteriorated Pavement Sections. In terms of applying the permutation algorithm to the area maximization problem of pavement rehabilitation, the costs of rehabilitation overlays shown in Table 1 are considered, as well as the specified budget limitations of this study. The optimization problem can be solved using the permutation algorithm, based on the setup shown in Table 2. For the simplicity of applying the permutation algorithm, the section numbers shown in Table 2 are sequentially assigned in ascending order, in terms of the integral SPI values.

\section{Results}

Our permutation algorithm was used to evaluate 150 pavement sections being considered for rehabilitation, as shown in Table 2. According to Step 3, the worst-first sequence was stored in the PM matrix, and the second row was obtained by randomly permutated selection, as shown in (9).

Permutation memory (PM) matrix generation for worstfirst maintenance, along with the first permutation, is as follows:

$$
\mathrm{PM}=\left[\begin{array}{ccccccccc|c}
1 & 2 & 3 & \cdots & \cdots & 27 & 28 & 29 & 30 & 262860 \\
12 & 50 & 45 & \cdots & 24 & 0 & 0 & 0 & 0 & 257020
\end{array}\right] .
$$

There were 50 sections that had an integral SPI value of $<5$. The 30 sections in the first row can be rehabilitated, using a limited budget of seven billion won (Korean currency), as shown in (9). The second row was updated until the second row chosen by the permutation algorithm provided more rehabilitated areas, compared with the first row of the worstfirst sequence. The rehabilitated sections were limited to 25 sections, which provided more rehabilitated area than the approach using worst-first maintenance, as shown in (10).

PM matrix consisting of a better solution in the second row, compared with the worst-first maintenance, is as follows:

$$
\mathrm{PM}=\left[\begin{array}{ccccccccc|c}
1 & 2 & \cdots & 25 & 26 & 27 & 28 & 29 & 30 & 262860 \\
50 & 26 & \cdots & 27 & 0 & 0 & 0 & 0 & 0 & 275580
\end{array}\right]
$$




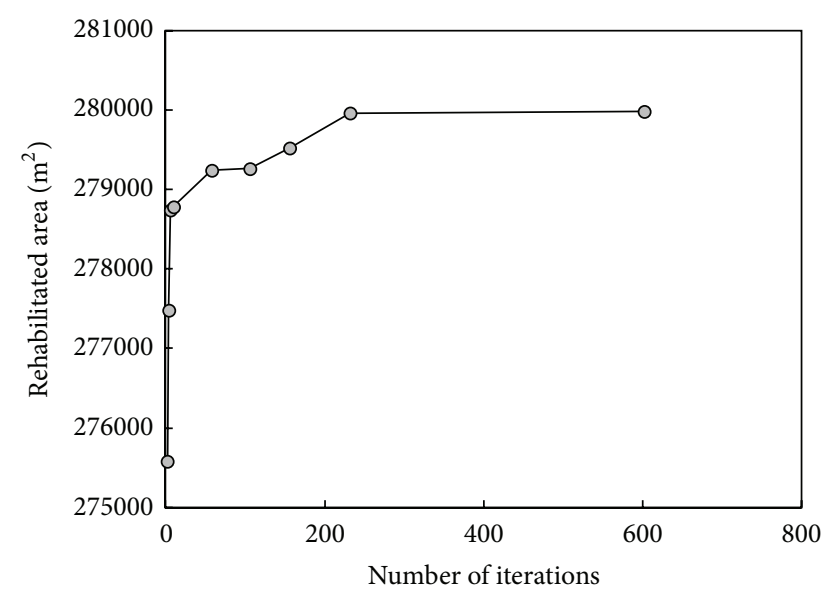

FIGURE 4: Rehabilitated area as a function of the number of iterations.

The columns above 25th in the second row of the PM matrix were assigned a zero value, as shown in (10). Additionally, a third row was added to the PM matrix when the randomly generated third row resulted in better selection than the second row group, in terms of rehabilitation area covered by the limited budget, as shown in (11). Equation (12) and Figure 4 show the best selection resulting in the largest rehabilitation area, after $\sim 1000$ iterations.

PM matrix updating procedure

$$
\mathrm{PM}=\left[\begin{array}{ccccccccccc|c}
1 & 2 & 3 & \cdots & 24 & 25 & 26 & 27 & 28 & 29 & 30 & 262860 \\
50 & 26 & 23 & \cdots & 19 & 27 & 0 & 0 & 0 & 0 & 0 & 275580 \\
29 & 17 & 47 & \cdots & 9 & 0 & 0 & 0 & 0 & 0 & 0 & 277480
\end{array}\right]
$$
rithm

Final PM matrix obtained using the permutation algo-

$$
\mathrm{PM}=\left[\begin{array}{ccccccccccc|c}
1 & 2 & 3 & \cdots & 24 & 25 & 26 & 27 & 28 & 29 & 30 & 262860 \\
50 & 26 & 23 & \cdots & 19 & 27 & 0 & 0 & 0 & 0 & 0 & 275580 \\
29 & 17 & 47 & \cdots & 9 & 0 & 0 & 0 & 0 & 0 & 0 & 277480 \\
53 & 14 & 58 & \cdots & 16 & 30 & 25 & 0 & 0 & 0 & 0 & 278740 \\
14 & 19 & 11 & \cdots & 49 & 58 & 2 & 46 & 41 & 12 & 31 & 278780 \\
5 & 9 & 12 & \cdots & 58 & 0 & 0 & 0 & 0 & 0 & 0 & 279240 \\
18 & 20 & 33 & \cdots & 9 & 45 & 36 & 26 & 43 & 27 & 0 & 279260 \\
37 & 26 & 41 & \cdots & 8 & 21 & 11 & 3 & 0 & 0 & 0 & 279520 \\
30 & 2 & 50 & \cdots & 26 & 21 & 9 & 0 & 0 & 0 & 0 & 279960 \\
38 & 27 & 46 & \cdots & 16 & 23 & 58 & 42 & 28 & 47 & 0 & 279980
\end{array}\right] .
$$

\section{Conclusion}

A permutation algorithm has been described to determine the optimal pavement rehabilitation planning which maximizes the rehabilitation area, using the empirical models of fatigue and rutting deterioration, as well as the functional model of IRI. To evaluate the suggested permutation algorithm, the worst-first maintenance method used in the current rehabilitation technique was compared. Our results indicated that the developed permutation algorithm, described in this study, provided a better solution in terms of covering a larger deteriorated area within the limited city budget, when compared with the worst-first maintenance, which is currently used in Seoul city.

\section{Acknowledgment}

This work was supported by the National Research Foundation of Korea (NRF) Grant funded by the Korea government (MEST) (no. 2011-0030848).

\section{References}

[1] R. Hass, W. R. Hudson, and J. Zaniewski, Modern Pavement Engineering, Krieger Publishing Company, Malabar, Fla, USA, 1994.

[2] M. W. Sayers and S. M. Karamihas, "Interpretation of road roughness profile data," Final Report Contract DTFH 61-92C00143, Federal Highway Administration, 1996.

[3] S. Mun and Z. W. Geem, "Determination of viscoelastic and damage properties of hot mix asphalt concrete using a harmony search algorithm," Mechanics of Materials, vol. 41, no. 3, pp. 339353, 2009.

[4] S. Mun and Z. W. Geem, "Determination of individual sound power levels of noise sources using a harmony search algorithm," International Journal of Industrial Ergonomics, vol. 39, no. 2, pp. 366-370, 2009.

[5] Y. Suh, S. Mun, and I. Yeo, "Fatigue life prediction of asphalt concrete pavement using a harmony search algorithm," KSCE Journal of Civil Engineering, vol. 14, no. 5, pp. 725-730, 2010.

[6] Z. W. Geem, "Particle-swarm harmony search for water network design," Engineering Optimization, vol. 41, no. 4, pp. 297311, 2009.

[7] J. Fourie, R. Green, and Z. W. Geem, "Generalized adaptive harmony search: a comparative analysis of modern harmony search," Journal of Applied Mathematics, vol. 2013, Article ID 380985, 13 pages, 2013. 


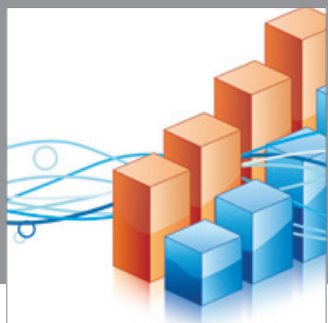

Advances in

Operations Research

mansans

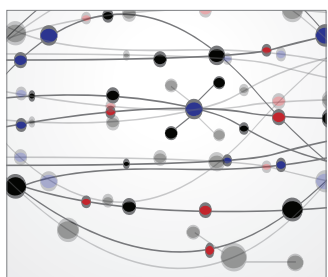

The Scientific World Journal
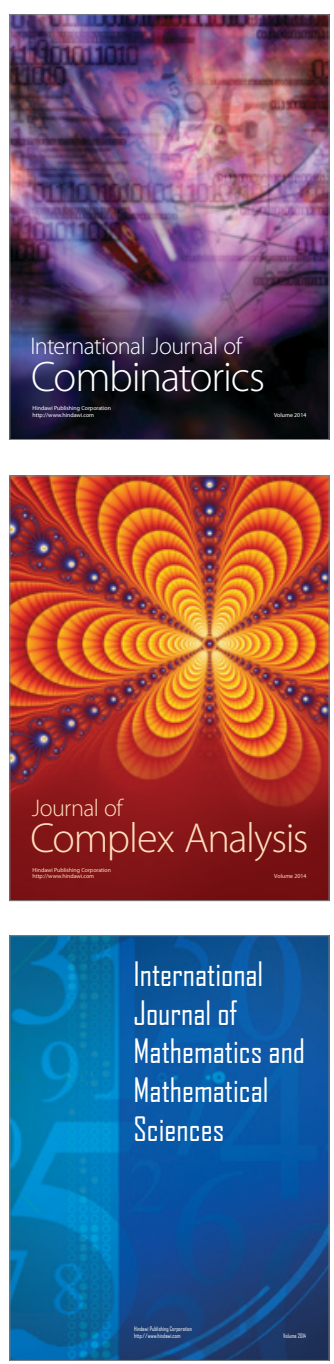
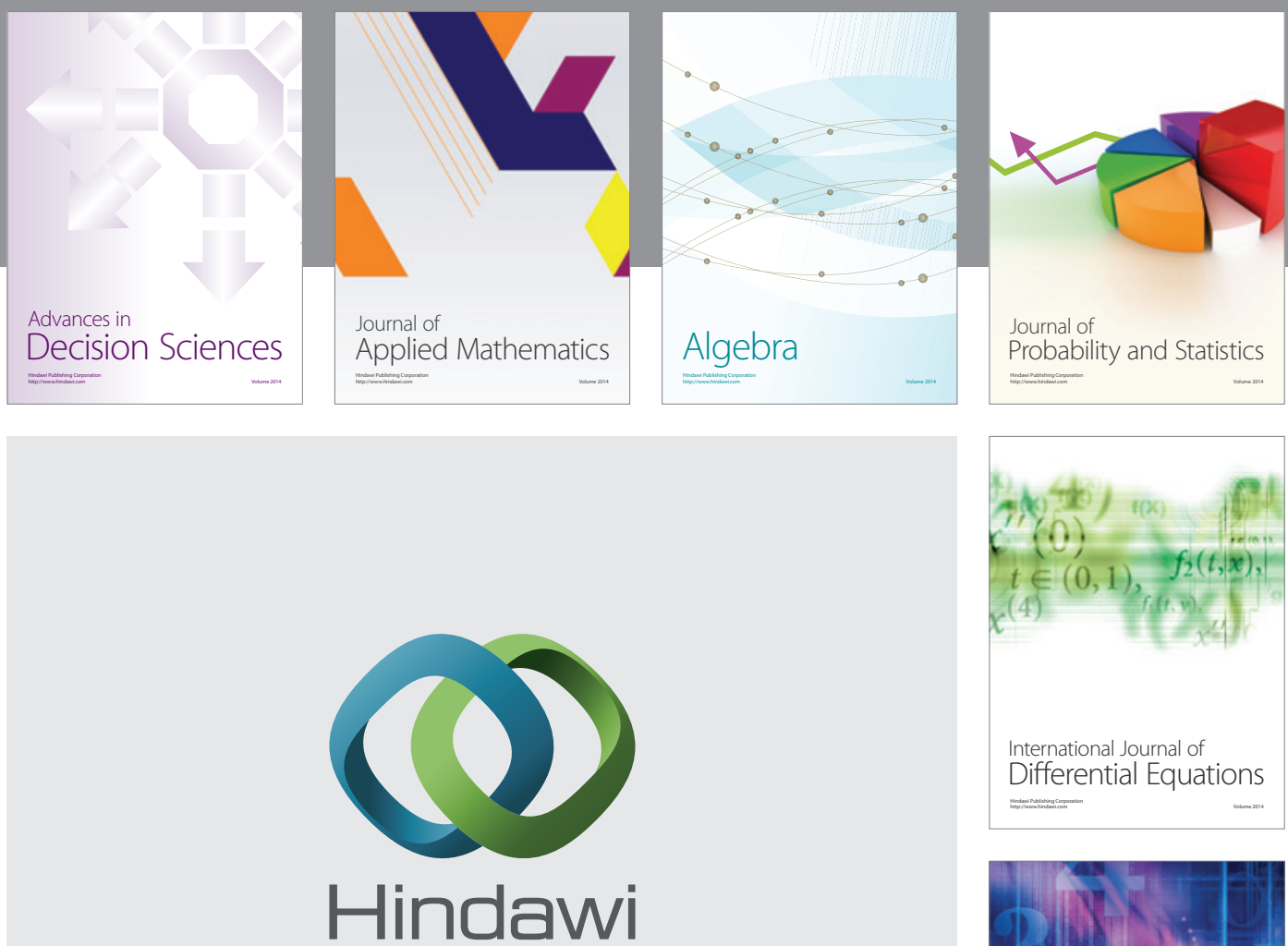

Submit your manuscripts at http://www.hindawi.com
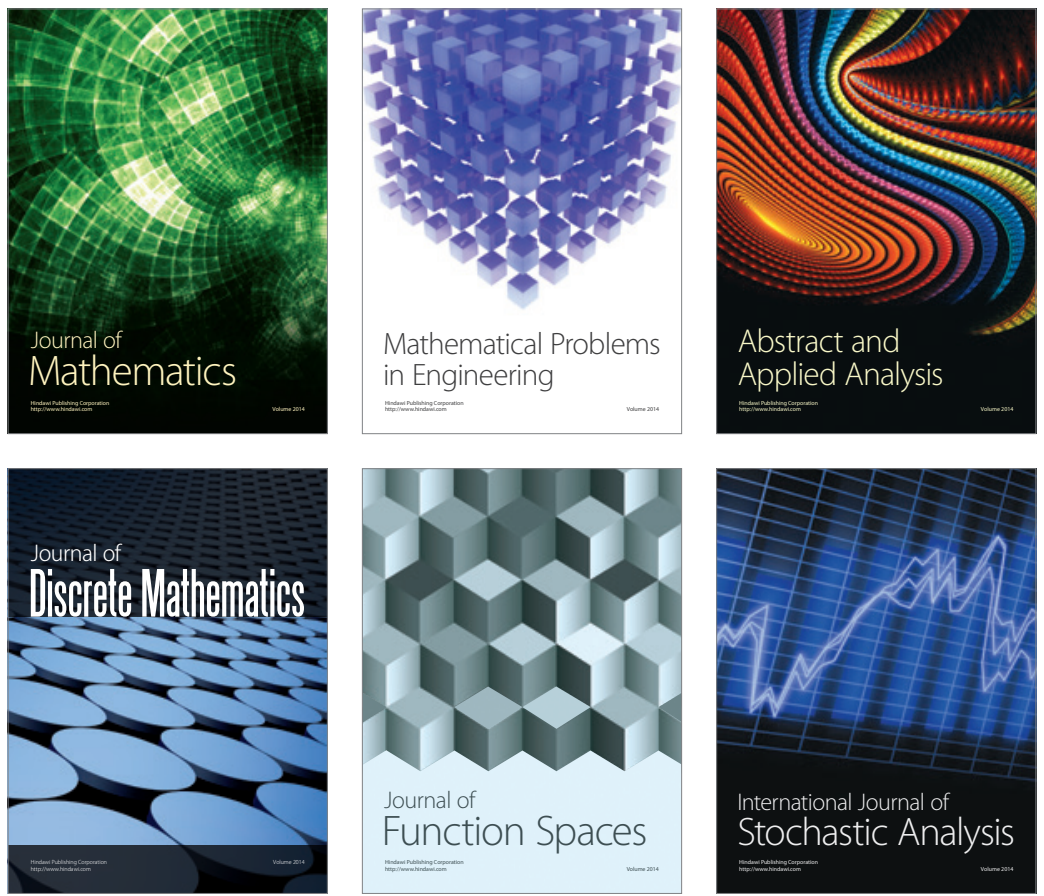

Journal of

Function Spaces

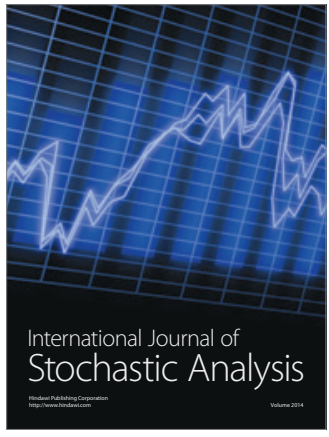

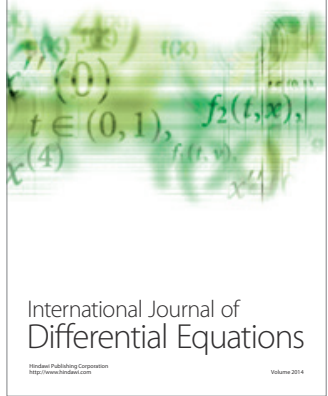
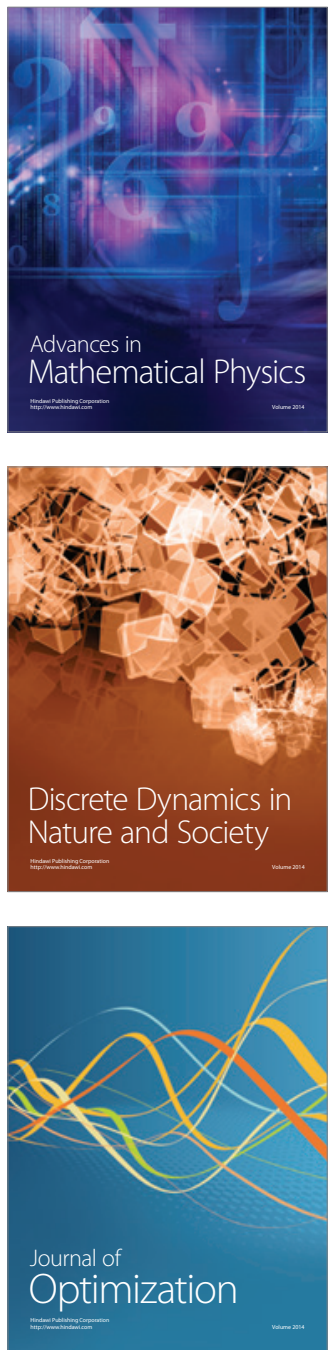